\title{
THE RECONSTRUCTION OF THE HISTORICAL BUILDING OF THE LATIN SCHOOL IN MALBORK
}

\author{
ZENON DUdA, KaTARZyna KRYZia \\ AGH University of Science and Technology, Kraków.
}

\begin{abstract}
The paper summarizes the reconstruction of the historical building erected in the 14th century, during the times of the residence of Grand Master of the Teutonic Order Winrich von Kniprode, currently referred to as the Latin School. It characterizes the location of the Latin School in the urban conservation area of the town of Malbork. The building is situated in the stretch of the buttressed brick escarpment on the Nogat River in the line of the historic defensive walls of Malbork.

The paper also outlines the history of this building, constructed and managed by the municipal authorities of Malbork, which for a long time was a seat of a Patronage of Saint George and the Merchant Guild, and next, from the 16th century until 1864, the building housed a school where basic Latin was taught. Next, the situation of this historical monument in the 20th century is discussed.

In the next part of the paper, the geological conditions of the site where the building was erected are discussed. The conducted archeological and architectural exploratory research related to the historical building with a particular emphasis on historic preservation and restoration works focusing on the building and its surroundings is presented and analyzed. Currently carried out design, construction and adaptation works allowing new functions to be embedded into this building are also discussed.

The paper shows the benefits due to the realization of the reconstruction program of the degraded building of the Latin school in the historic quarter of the town. These activities are aimed at the conversion of the currently derelict building by means of embedding new functions into it. There are being designed, among others, an interactive educational center modern library, astronomical observatory, craft museum and multifunctional hall, allowing proper conditions to be created for the development of educational, artistic and tourism related activities in the reconstructed building.

The reconstruction of the historical building is a positive response to its deterioration resulting from former activities and it will contribute to the improvement of the quality of cultural life of both local inhabitants and visitors.
\end{abstract}

\section{INTRODUCTION}

The dynamic development of civilization in the 20th century necessitated the sophistication of scientific and technological activities meant to solve complex problems resulting from the past and also from present-day requirements. One of the directions of these activities is the broadly understood conservation of archeological and historical/architectural sites constituting the wealth of the material culture of a given nation.

Cultural heritage sites, weakened by the passage of time, endangered by shortsighted human activities and deteriorating ecological conditions of the natural environment frequently require taking measures aimed at stopping the ongoing degradation process, eliminating the reasons for the damage and restoring these sites to their former historic and functional value. 
Activities leading to the reconstruction of a building have to be complex and permanent in nature, which can be attained by the realization of tasks the aim of which is not only eliminating the results but also, and primarily, the hazards contributing to the degradation of a historic building. Most often tasks performed to realize this purpose include subsoil surveys and, if necessary, soil stabilization and drainage activities, and also protecting the underground floors and foundations of the building. The completion of these works is an indispensable requirement for undertaking preservation and restoration works in the overground floors of a historical building.

The brick building of the Latin School, dating from the 14th century, is an example of such approach to the cultural heritage preservation within the urban conservation area of the town of Malbork. The current state of the building, located in the stretch of medieval fortifications, requires undertaking complex reconstruction activities, which would allow for introducing infrastructural functions pertaining to the development of cultural, tourism-related and educational activity.

The realization of the reconstruction program of the historic building of the Latin School is supposed to create in the degraded municipally owned structure new chances and opportunities pertaining to general development, for inhabitants of the areas neighbouring the restored building, with a view of preserving its cultural heritage.

\section{THE LATIN SCHOOL IN MALBORK - HISTORY}

The historical building of the Latin School, erected and managed by the municipal authorities of the town of Malbork, dates from the 14th century and the reign of Grand Master of the Teutonic Order Winrich von Kniprode. The building is located in the stretch of the buttressed brick escarpment on the Nogat River in the line of the historic defensive walls of Malbork [11].

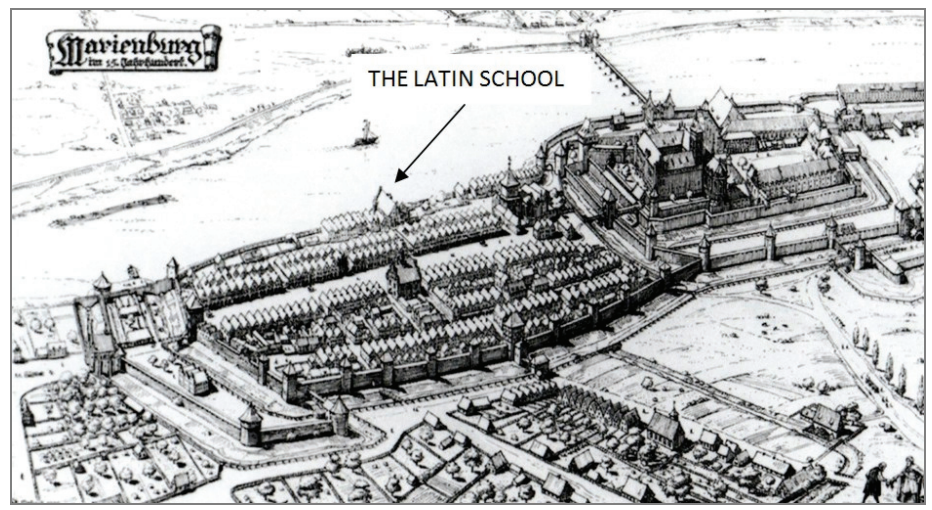

Fig. 1. The location of the Latin School in relation to the Castle and the town of Malbork (the 15 th century view according to C. Steinbrecht's reconstruction) 
Originally, Malbork, a medium-sized town concerning its area, settlement development and economy being artisanal, commercial and agricultural in character, developed owing to its favourable waterway connections with the Nogat and Vistula Rivers. At that time the building in question presumably acted as a seat of the Merchant Guild, where grain, timber, animal skins, horses and wine were traded among other things. For a long time, supposedly, a Patronage of Saint George was based there as well. Next, from the 16th century until 1864, the building functioned as a school where basic Latin was taught. It was destroyed in the fire which spread through the town in 1899 , and was rebuilt in 1900 as a typical warehouse [1], [2], [8]. Another fire in 1945 ruined the building. Due to its heritage value, a documentation of its reconstruction and site planning was prepared in 1971, but the construction works carried out by Historical Monuments Preservation Department (Pracownia Konserwacji Zabytków) were suspended because of the lack of sufficient funding and were restricted only to a partial restoration and reconstruction of the doors and staircases. In 1978, the building was taken over by the Youth Centre (Młodzieżowy Dom Kultury), which converted it into a water sports centre (Fig. 2) [4], [7].

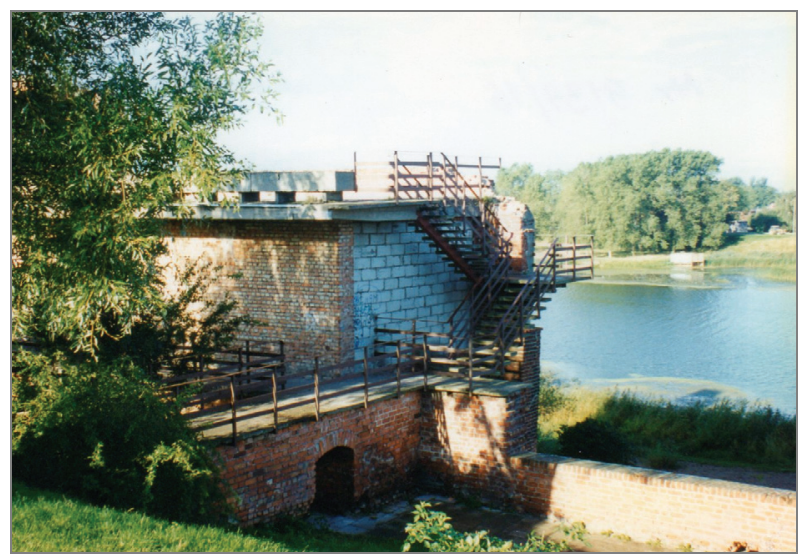

Fig. 2. The Latin School after its partial restoration in the 1970s (photograph by Z. Duda)

For a long time the preserved parts of the building have represented merely fractions of the medieval enclosure and now the building is undergoing reconstruction aiming at converting the former function of the Latin School into a new one [6], [7], [10].

\section{THE RECONSTRUCTION OF THE HISTORICAL BUILDING OF THE LATIN SCHOOL}

Currently the reconstruction of the building is being supervised by the Malbork town administration. The intention of the investor is to convert the historical building 
so that it could assume new functions promoting cultural, tourism-related and educational activities.

The scope of the project embraces the following elements: the reconstruction of the historical building, introduction of new functions pertaining to general development, site planning of the areas surrounding the building and partial restoration of the defensive walls around the building [12], [13].

The preliminary stage of the reconstruction of the Latin School included archeological (Fig. 3) and geological studies which allowed the selection and application of the proper kind of foundations and the drainage system in the existing soil and hydrological conditions [3], [14].

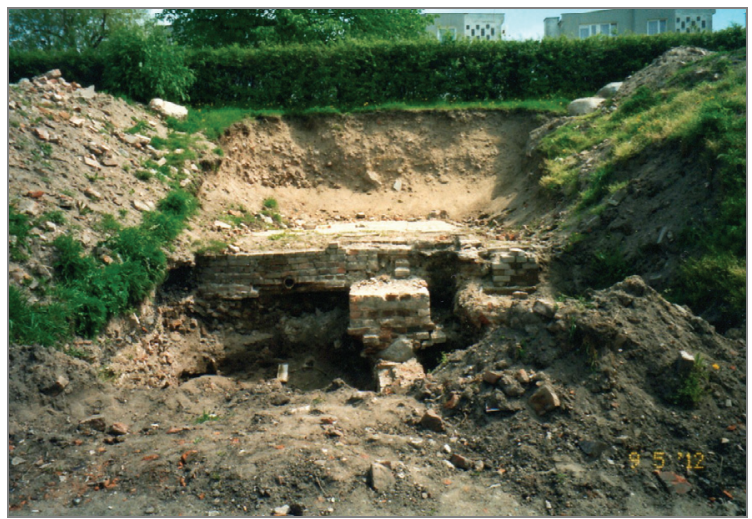

Fig. 3. Excavation site, May 2012 (photograph by Z. Duda)

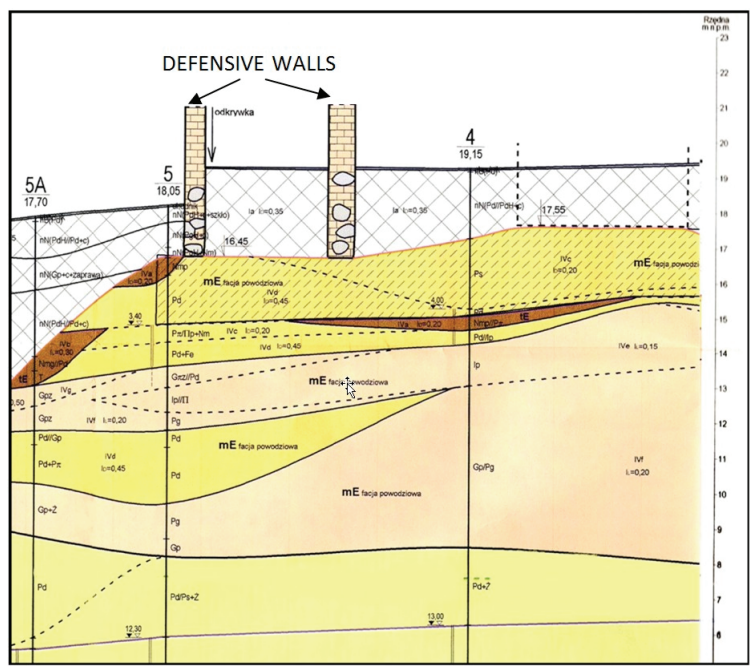

Fig. 4. A soil-profile in the region of the defensive walls [5] 
Both the defensive walls and the Latin School are located on postglacial rock deposits. The soil profile showing the sequence of the layers in banks of the Nogat River is illustrated in Fig. 4. Postglacial rock deposits are composed mostly of clay-loam, sand loam and fine sand with numerous fine rock fractions. They contain also heavy loam rich in clay, proglacial clays, sand pockets, sandy gravel and gravel [4], [5].

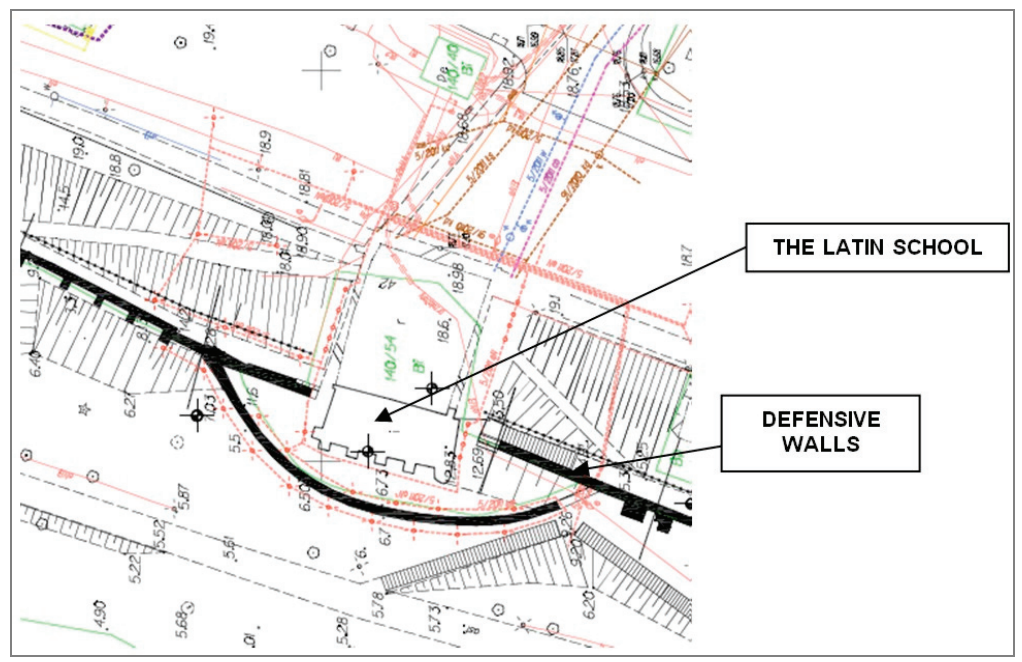

Fig. 5. Plan of land development [14]

The foundations of the building will be located on a system of reticulated root piles with reinforced concrete skeleton construction and a slab on grade. Further construction works will involve a partial removal of the original walls and ceilings and then constructing a four-storey slab-on-grade building with a pitched roof. The building, fitted with all the installations, will be reconstructed in accordance with the traditional brick-and-mortar technology with reinforced-concrete columns supporting the structure of the pitched roof. Figures 6 through 9 show the current state of progress of the construction works and the "to be" situation.

After the completion of the construction works, the project will proceed to the stage of furnishing the reconstructed historical building of the Latin School with electronic equipment and multimedia, embellishing it, providing sanitation and hygiene facilities and organizing the exhibition of the craft museum. Due to all these works both inhabitants and tourists will be provided with the opportunity to use a modern educational center. The building will house, among others, a state-of-the-art, fully computerized library, with multi-terminal access to the Internet, astronomical observatory, interactive educational center enabling to further the knowledge gained within the traditional education system, craft museum and multifunctional hall used for cultural and social purposes. 


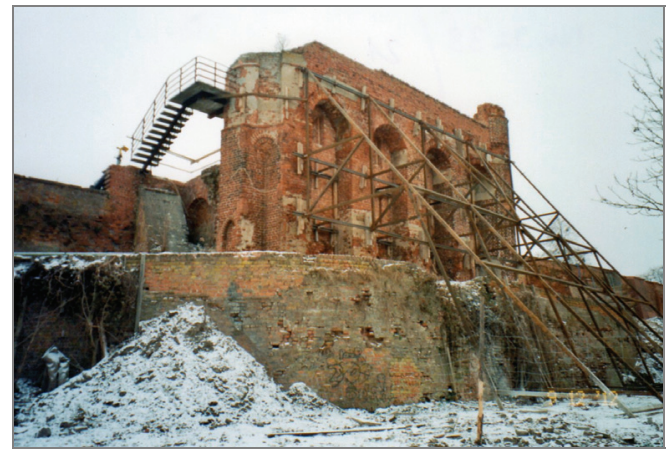

Fig. 6. The state of progress of the construction works, December 2012; the north-west side view (photograph by Z. Duda)

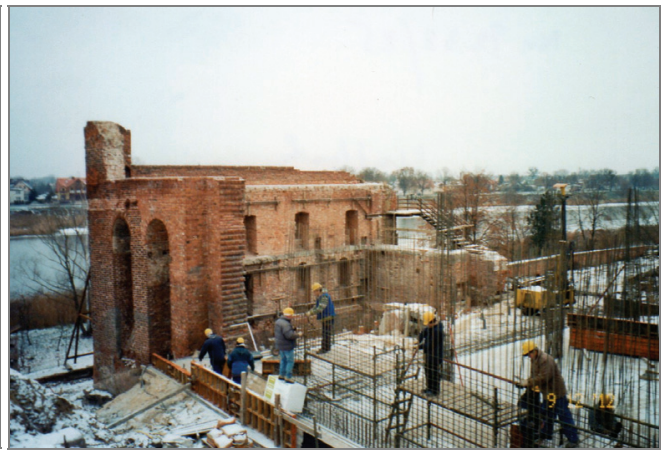

Fig. 7. The state of progress of the construction works, December 2012; the south-east side view (photograph by Z. Duda)

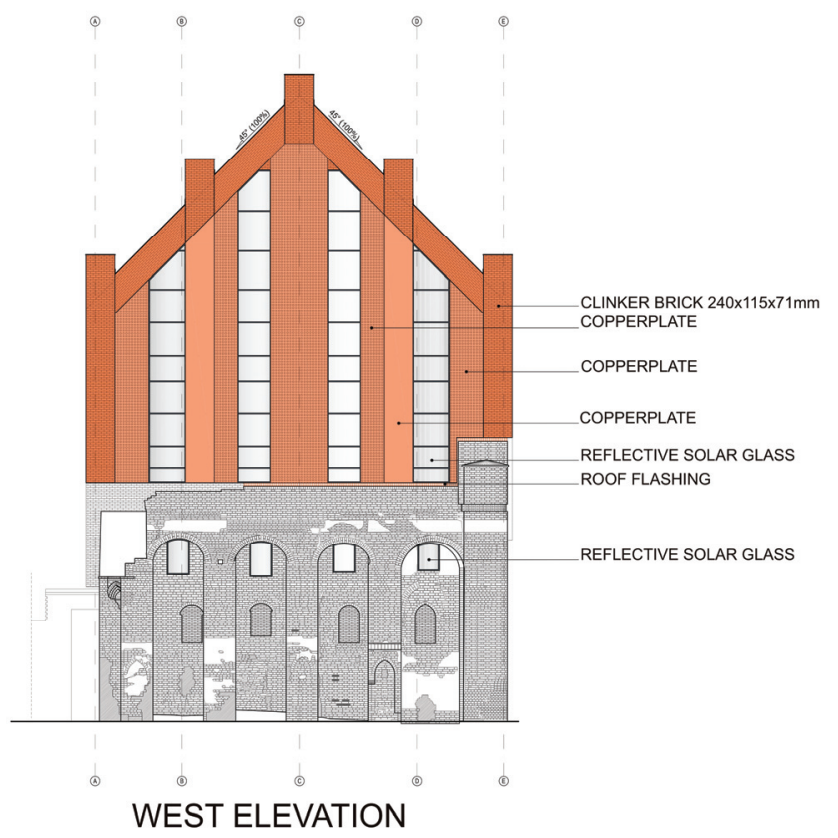

Fig. 8. The west facade design of the Latin School in Malbork [3]

Other works included in the reconstruction project of the Latin School are land development works in the area around the building (Fig. 5). In particular, they will comprise road surfacing, providing pedestrian walkways, landscaping, installing benches, trashcans, road signs and information plaques. All these elements will account for the overall orderly and aesthetic appearance [12], [13]. 


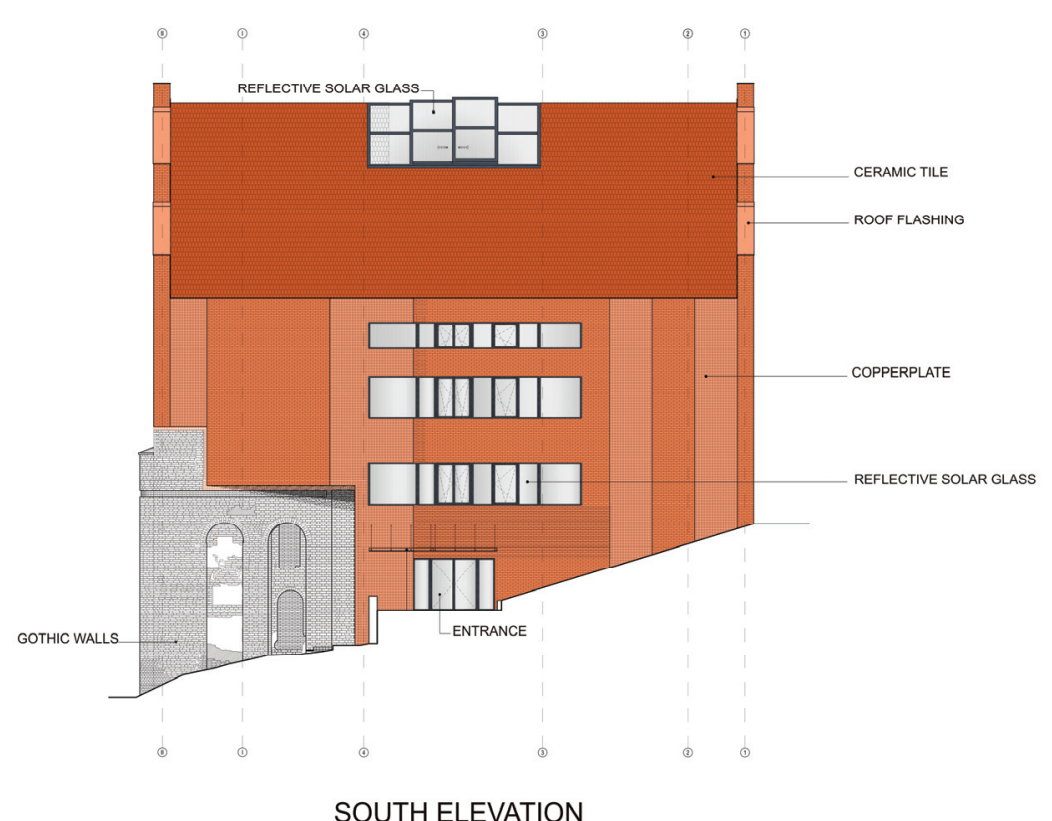

Fig. 9. The south facade design of the Latin School in Malbork [3]

One more aim which will also be accomplished is the restoration of the old medieval defensive walls surrounding the building of the Latin School. The restoration will involve removing old plaster from the walls, abrasive blasting of the walls, pilasters and cornices and renovating the thick Gothic walls by completing them with the missing elements and exchanging the binding material. Moreover, a biocidal impregnation, anti-salt protection and water proofing of the brick surface of the walls and their coping as well as their insulation below the ground will also be performed in the course of the reconstruction [14].

\section{SUMMARY}

On the basis of the synthetic characteristics of the endangered historic building and the works related to its conservation it is possible to conclude that:

The reconstructed historical part of the defensive walls, and, in particular, the building of the Latin School, which was left to decay for a long time, gradually deteriorating, will provide a unique cultural and recreational offer for both the inhabitants of Malbork and tourists.

After the reconstruction and introduction of new, modern functions into the building, the Latin School will be inspirational from a social point of view, allowing for 
a number of different methods for educating the public and acquainting people with the old craftsmanship.

In the reconstructed historical building of the Latin School in Malbork it is possible to boost tourism thanks to the modernization works and restoration of the fortifications.

The reconstruction of the building is a positive response to the decrepit state of the building caused by former activities and it will contribute to improving the quality of the cultural life of the inhabitants of the region.

\section{REFERENCES}

[1] Biskup M., Labuda G., The history of the Teutonic Order in Prussia, (in Polish), Gdańsk, 1988.

[2] Bogdanowski J., Defensive architecture in the landscape, Polish Scientific Publishers, (in Polish), Kraków, 2002.

[3] DUDA Z., A comprehensive program of preparatory work for the development of the concept and technical design of repair and maintenance of the medieval walls of Malbork, (in Polish), Kraków, 1997 (unpublished).

[4] Duda Z., The project of potential rescue-intervention works of parts of the historic walls of Malbork (in Polish), Kraków, 1998 (unpublished).

[5] Duda Z., Kryzia K., Malbork city fortified walls, (in Polish), Górnictwo i Geoinżynieria, Kraków, nr 35, z. 2, 2011, 191-199.

[6] HaftKa M., Malbork: album - guide: historical and other information about the monuments, (in Polish), Warszawa, 2000.

[7] JEDLIŃSKI W., Malbork: the history of the city, (in Polish), Malbork.

[8] Jesionowski B., Archival materials, (in Polish), Malbork, 2012.

[9] Kozarski P., Molski P., Development and maintenance of historic buildings (Fortification Volume XIV), (in Polish), Warszawa, 2001.

[10] MierzwiŃSKi M., HAfTKA M., Malbork. Castle of the Teutonic Order, (in Polish), Warszawa 1992.

[11] Murinius M., Champions Prussian Chronicle, (in Polish), Olsztyn, 1989.

[12] Collective work, Local Revitalization Program for the City of Malbork for 2007-2013, (in Polish), Office of Malbork and Faber Consulting Sp., Ltd., Torun, 2007.

[13] Collective work, Reconstruction and the introduction of new features in the Latin School in Malbork, (in Polish), Office of Malbork and Workshop Inwestproj, 2012.

[14] TCHÓRZEWSKI Z., Building Project protection of groundwater inflow walls of the Old Town estate, (in Polish), Malbork, 2012. 